\title{
PERCEPÇÃO DE CONSUMIDORES DO RIO GRANDE DO SUL EM RELAÇÃO A QUESITOS DE QUALIDADE EM FRUTAS ${ }^{1}$
}

\author{
CESAR VALMOR ROMBALDI ${ }^{2}$,CASIANE SALETE TIBOLA ${ }^{3}$, JOSÉ CARLOS FACHINELLO ${ }^{4}$, \\ JORGEADOLFO SILVA ${ }^{5}$
}

RESUMO- Objetivando identificar os principais quesitos de qualidade na tomada de decisão para adquirir e consumir frutas e suas possíveis inter-relações com faixa etária, sexo, grau de instrução e renda, foi realizada pesquisa com consumidores de frutas do Estado do Rio Grande do Sul. O experimento foi realizado em seis municípios (Porto Alegre, Pelotas, Santa Maria, Caxias do Sul, Passo Fundo e Santa Rosa). O método utilizado foi o descritivo, e os dados foram coletados através de questionário, entrevistando-se 1.040 pessoas. Os quesitos apresentados (variáveis) foram: preço; aparência, sabor e aroma; embalagem; regularidade de oferta (facilidade para encontrar o produto); marca; vida de prateleira (durabilidade); praticidade (fácil de transportar e utilizar); ausência de resíduos de agrotóxicos; origem; certificação; meio ambiente; valor nutricional; valor funcional; valorização de aspectos socioculturais; outros. De acordo com os consumidores, independentemente de idade, sexo, grau de instrução e renda, os atributos preço; aparência, sabor e aroma; ausência de resíduos de agrotóxicos e identificação da origem são, em ordem decrescente, os principais quesitos para a tomada de decisão para comprar ou não uma determinada fruta.

Termos para indexação: consumo, preço, rastreabilidade e qualidade sensorial.

\section{PERCEPTION OF RIO GRANDE DO SUL CONSUMERS ABOUT FRUIT QUALITY QUESTIONS}

\begin{abstract}
To identify the main quality questions considered for decision to acquire and consume fruits and its possible relation with age, sex, instruction and income category, we carried out this research with consumers of fruits in Rio Grande do Sul State. The experiment was carried out in six cities (Porto Alegre, Pelotas, Santa Maria, Caxias do Sul, Passo Fundo and Santa Rosa). The methodology used was descriptive research for statistical method and the data were collected by questionnaire, in the form of personal interview with 1040 people. The attributes (variables) questioned were related with the price; appearance, flavor and aroma; packing; regularity of offers (easiness to find the product); mark; shelf life (durability); practical (easy to carry and to use); without residues of pesticides; origin; certification; environment; nutritional value; functional value; valuation of cultural aspects; others. According to the consumers, independent of the age, sex, instruction and income category, price; appearance, flavor and aroma; absence of residues of pesticides and identification of the origin, in decreasing order of importance, are considered the most important attributes at the purchase. Index terms: consume,traceability, price and sensorial quality.
\end{abstract}

A amplitude de mercados no cenário vigente estimula a competitividade e a busca de eficiência e eficácia para garantir rentabilidade continuada. Para tanto, o foco principal da cadeia produtiva deverá ser o atendimento das necessidades e das exigências dos consumidores. A comercialização no setor frutícola é dependente de apreciação positiva pelo consumidor, que, segundo Gutierrez (2005), está relacionada principalmente com a aparência e as características sensoriais, além da garantia de segurança e qualidade, possibilitando o estabelecimento de estratégias diferenciadas de comercialização, e a orientação de programas de melhoramento genético de plantas frutíferas.

A produção de alimentos deve ser certificada de acordo com normativas, como as da Produção Integrada de Frutas (PIF), Produção Orgânica (PO), de Análise de Perigos e Pontos Críticos de Controle (APPCC) e de sistemas de rastreabilidade. Essas normativas objetivam, de maneira geral, a proteção dos recursos naturais, a minimização no uso de agrotóxicos, $\mathrm{o}$ atendimento aos requisitos sociais, a proteção da saúde humana (produtores, colaboradores e consumidores), a garantia da qualidade e da segurança dos alimentos (Andrigueto \& Kososki, 2005).

A esses sistemas, incorporam-se outros conceitos, com a finalidade de assegurar e valorizar a origem das frutas, bem como associá-las ao sistema de produção, não apenas de ponto de vista tecnológico, mas também de suas inter-relações com a

${ }^{1}$ (Trabalho 195-06). Recebido em :27-11-2006. Aceito para publicação em : 17-07-2007.

${ }^{2}$ Eng. Agr ${ }^{\circ}$. Dr., Professor Titular do Departamento de Ciência e Tecnologia Agroindustrial - FAEM/UFPel. Cx. Postal: 354, CEP: 96010-900. Pelotas - RS. cesarvrf@ufpel.tche.br

${ }^{3}$ Eng. Agr. ${ }^{a}$ Dra ., Pesquisadora Embrapa Trigo- Rod. BR 285, Km 294 -CEP 99001-970. Passo Fundo-RS. casiane@cnpt.embrapa.br.

${ }^{4}$ Eng. Agro . Dr., Professor Titular do Departamento de Fitotecnia - FAEM/UFPel. jfachi@ufpel.tche.br

${ }^{5}$ Eng. Agr ${ }^{\circ}$. Dr., Professor Adjunto do Departamento de Ciência e Tecnologia Agroindustrial - FAEM/UFPel.

Rev. Bras. Frutic., Jaboticabal - SP, v. 29, n. 3, p. 681-684, Dezembro 2007 
inserção de trabalho, redução de insumos e de dependência científico-tecnológica. Surgem, nesse contexto, as denominações de origem, indicações geográficas e de procedência (Llopis, 1997). Além disso, tem havido uma crescente geração de conhecimento demonstrando benefícios que o consumo de frutas traz ao consumidor, especialmente pelos aspectos nutricionais e funcionais, ambos importantes na melhoria da qualidade de vida (Liu, 2006).

Em pesquisa realizada na década de 80 com consumidores no Brasil, objetivando evidenciar os principais requisitos de qualidade para frutas, obtiveram-se os seguintes resultados, em ordem decrescente de importância: preço, aparência, embalagem, regularidade de oferta, marca, vida de prateleira, praticidade, nãodetecção de resíduos de agrotóxicos e origem (Watada, 1980). Acredita-se, no entanto, que, com a ampliação da oferta, a evolução nos conhecimentos e nos sistemas de informação, tenha havido alteração desse perfil de percepção, incorporando-se novos quesitos e/ou alterado o grau de importância daqueles mencionados naquela pesquisa.

Assim, buscou-se identificar os principais quesitos de qualidade para os consumidores do Estado do Rio Grande do Sul, na tomada de decisão ao adquirir e consumir frutas e suas possíveis inter-relações com faixa etária, sexo, grau de instrução e renda.

$\mathrm{O}$ experimento foi realizado em seis municípios (Porto Alegre - 410 entrevistados, Pelotas - 130 entrevistados, Santa Maria- 110 entrevistados, Caxias do Sul- 130 entrevistados, Passo Fundo- 90 entrevistados, Santa Rosa- 70 entrevistados, totalizando 1.040 pessoas. As entrevistas foram realizadas em supermercados, feiras livres, fruteiras e minimercados.

Por ocasião de cada entrevista, registrou-se, em ficha individual, o local onde a coleta de dados estava sendo processada, bem como a idade, o sexo, a escolaridade e a renda mensal de cada entrevistado(a). A partir daí, coletou-se resposta a questões em uma ficha, na qual estavam listados 15 quesitos de qualidade, estabelecidos a partir de ensaio-piloto no qual se questionaram 450 consumidores, através de pesquisa nãoinduzida, sobre os critérios adotados para aquisição de frutas. Os quesitos apresentados foram: preço; aparência, sabor e aroma; embalagem; regularidade de oferta (facilidade para encontrar o produto o ano todo); marca; vida de prateleira (durabilidade); praticidade (fácil de transportar e utilizar); ausência de resíduos de agrotóxicos; origem; certificação; meio ambiente; valor nutricional; valor funcional; valorização de aspectos socioculturais; outros. A ordem dos itens foi distribuída ao acaso em cada grupo de 50 fichas, de modo a evitar a indução na escolha priorizada. A cada entrevistado(a), foi solicitado que marcasse os cinco quesitos mais importantes. Explicou-se, também, que outros quesitos adicionais poderiam ser citados pelos entrevistados. Além disso, foram registradas, nas fichas da entrevista, as manifestações espontâneas dos entrevistados.

Ao final da coleta de dados, realizou-se a tabulação por município, local de coleta, faixa etária ( 0 a 16 anos; 16 a 25 anos; 25 a 50 anos, ou mais do que 50 anos), sexo, escolaridade (primeiro grau completo ou incompleto, segundo grau completo ou incompleto, terceiro grau ou pós-graduação) e renda mensal individual (até 2 salários mínimos; 2 a 5 salários; 5 a 10 salários, ou mais de 10 salários).

Do total de 1.040 entrevistados, $48 \%$ foram do sexo masculino e $52 \%$ do sexo feminino (Tabela 1 ). Em relação à distribuição quanto à faixa etária, $18 \%$ dos entrevistados tinham até 16 anos; $22 \%$ entre 16 e 25 anos; $42 \%$ entre 25 e 50 anos, e $18 \%$ (187) com mais de 50 anos. Ao analisar-se a distribuição quanto à escolaridade, verificou-se que $37 \%$ tinham, no máximo, primeiro grau completo ou incompleto; $42 \%$ segundo grau completo ou incompleto; $16 \%$ terceiro grau completo ou incompleto, e $5 \%$ pósgraduação completa ou incompleta. Quanto à renda mensal individual, 33\% recebem menos do que dois salários mínimos; $42 \%$ entre 2 e 5 salários; $16 \%$ entre 5 e 10 salários, e $9 \%$ mais de 10 salários (Tabela 1).

Ao iniciarem-se os estudos, emitiu-se a hipótese de que, no mínimo, uma das variáveis de estruturação demográfica da população estudada pudesse ter efeito sobre a priorização dos quesitos de qualidade das frutas; entretanto, essa afirmativa não foi confirmada. Não houve interação, nem efeito significativo das variáveis na priorização dos quesitos estudados. Independentemente da renda, da idade, da escolaridade, do sexo e do município, os quesitos majoritários foram os mesmos, sugerindo que a decisão de adquirir ou não uma determinada fruta é uma questão de caráter majoritariamente cultural, e não propriamente regional, etária ou sócioeconômica.

De um total de 5.200 respostas, cinco itens foram majoritariamente citados representando $52 \%$ das citações. Foram eles, em ordem decrescente de importância: preço; aparência, sabor e aroma; ausência de resíduos de agrotóxico e origem. Um segundo grupo, incluindo praticidade, marca, valor nutricional, valor funcional, vida de prateleira, meio ambiente, certificação e valores socioculturais, atingiu entre $3 \%$ e $7 \%$ das citações cada (Tabela 2).

Em pesquisa realizada com os responsáveis pelas compras de frutas e hortaliças na rede hoteleira de São Paulo e Rio de Janeiro, quanto à preocupação com agrotóxicos, $52 \%$ responderam que se preocupam, mas acreditam que um processo de higienização, quando bem realizado, reduz as contaminações nas frutas. Esses clientes procuram fidelização dos fornecedores e os responsabilizam por qualquer problema que possa haver quanto às contaminações. Complementarmente, citam que os principais problemas são: ausência de padronização e falta de sabor nas frutas (FrutiFatos, 2004).

De acordo com Watada (1980), os quesitos de maior relevância para os consumidores brasileiros de frutas, naquela época, eram: o preço, a tradição, a aparência, a embalagem, a regularidade de oferta, a marca, a vida de prateleira e a praticidade, nessa ordem decrescente de importância. Mesmo que a comparação entre a pesquisa realizada por Watada (1980) e esta não possa ser feita na sua totalidade, tendo em vista que os procedimentos de coleta foram distintos, podem-se estabelecer relações parciais. Por exemplo, em ambos os casos, o quesito preço permanece como o de maior importância na tomada de decisão em adquirir ou não um determinado produto. Uma das explicações prováveis desse comportamento é o fato de que $75 \%$ dos entrevistados recebem menos do que cinco salários mínimos 
mensais e, provavelmente, por isso, levam em consideração esse parâmetro, como prioritário na tomada de decisão para aquisição ou não de uma determinada fruta. Além disso, embora não fizesse parte do questionário, os entrevistados relataram que, com a ampliação da oferta de frutas, quando há aumento excessivo de preço em uma determinada espécie, buscam alternativas de menor valor em outras espécies (frutas da estação). Mesmo consumidores com maior renda destacam o preço como quesito para tomada de decisão, evidenciando que valores altos deslocam a compra para produtos locais e da estação, normalmente mais baratos e saborosos.

Em contrapartida, em pesquisa realizada com consumidores de supermercados mineiros, verificou-se que $60 \%$ consideram a qualidade como item de maior importância no momento de adquirir frutas, $18 \%$ consideram a aparência e 12\% afirmam ser o preço o fator mais relevante na decisão. Nessa pesquisa, a percepção de qualidade das frutas foi baseada em aspectos visuais, como maturação adequada, ausência de manchas e batidas (FrutiFatos, 2003).

No atual estudo, verificou-se que a aparência continua sendo um dos fatores de maior relevância na tomada de decisão para adquirir ou não determinada fruta. Isso já era esperado, pois é amplamente conhecido que o consumidor é fortemente atraído pelo aspecto do produto. A aparência geral, que inclui a padronização, coloração, ausência de lesões e podridões, aspecto de produto "fresco", associado ao aroma (perfume) e ao sabor, constitui-se um parâmetro mais importante, representando 12\% do total das 5.200 citações (Tabela 2).

A busca de produtos de origem conhecida e com garantia de segurança para o consumo completa o grupo dos cinco quesitos mais citados. Nesse particular, houve mudança do perfil em relação àquela da década de 80 , ou seja, naquele caso, origem e segurança, não se apresentavam entre os mais citados. Essa evolução se deve, provavelmente, ao fato de ter havido aumento da consciência da importância de se conhecer a procedência dos produtos, bem como de se exigir garantias quanto à sua segurança. Essa hipótese fica consubstanciada pelo fato de ter-se incluso quesitos de qualidade diferenciados, como é o caso do valor nutricional, do valor funcional, da certificação e do meio ambiente.

Por outro lado, outros quesitos mostraram redução em importância em relação a estudos precedentes, como é o caso de marca. Embora não se tenha realizado pesquisa específica para esclarecer as causas desse evento, acredita-se, a partir de manifestações espontâneas dos entrevistados, que o conhecimento da origem, valorizando características regionais, passou a ser mais relevante do que marca. Na pesquisa com os consumidores mineiros, também foi verificado o desejo dos consumidores em conhecer mais sobre as frutas, sendo que as informações mais solicitadas foram: a composição nutricional, a procedência, os benefícios à saúde e o sistema produtivo (FrutiFatos, 2003).

Houve uma minimização da importância do aspecto vida de prateleira dos produtos. Os consumidores afirmam que a deterioração rápida das frutas é um problema grave, mas salientam que as frutas que se conservam por mais tempo, em geral, apresentam deficiências no sabor e no aroma. Nesse caso, o exemplo mais citado pelos entrevistados é o tomate longa vida, que oferece a vantagem da alta conservação, mas é pobre em sabor, em aroma e em coloração.

Os principais quesitos para a tomada de decisão para comprar ou não uma determinada fruta são, em ordem decrescente de importância: o preço; a aparência, o sabor e o aroma; a ausência de resíduos de agrotóxicos e a identificação da origem, independentemente de faixa etária, sexo, escolaridade e renda.

TABELA 1- Caracterização dos entrevistados quanto ao sexo, faixa etária, escolaridade e renda mensal individual. Pelotas, 2006.

\begin{tabular}{l|l|l|l|l|l|l|l|l|l|l|l|l|l}
\hline \multicolumn{3}{c|}{ Sexo $^{1}$} & \multicolumn{4}{c|}{ Faixa etária $^{2}$} & \multicolumn{5}{c|}{ Escolaridade $^{3}$} & \multicolumn{5}{c}{ Renda $^{4}$} \\
\hline M & F & 1 & 2 & 3 & 4 & 1 & 2 & 3 & 4 & 1 & 2 & 3 & 4 \\
\hline 498 & 542 & 187 & 229 & 437 & 187 & 385 & 437 & 166 & 52 & 343 & 437 & 166 & 94 \\
\hline
\end{tabular}

${ }^{1} \mathrm{M}$ - masculino; F - feminino

${ }^{2} 1$ ( 0 a 16 anos); 2 (16 a 25 anos); 3 (25 a 50 anos); 4 (mais do que 50 anos)

${ }^{3} 1$ (1Ú grau completo ou incompleto); 2 (2Ú grau completo ou incompleto); 3 (3Ú grau); 4 (pós-graduação)

${ }^{4} 1$ (até 2 salários mínimos); 2 (2 a 5 salários); 3 (5 a 10 salários); 4 (mais de 10 salários)

TABELA 2 - Importância dos quesitos de qualidade, citados pelos consumidores, para aquisição de frutas no Rio Grande do Sul. Pelotas, 2006.

\begin{tabular}{l|l|l}
\hline Quesitos analisados & $\begin{array}{l}\text { Número } \\
\text { de citações }\end{array}$ & $\begin{array}{l}\text { Porcentagem } \\
\mathbf{( \% )}\end{array}$ \\
\hline Preço & 940 & 18 \\
Aparência, sabor e aroma & 640 & 12 \\
Embalagem & 154 & 3 \\
Regularidade de oferta (facilidade em encontrar o produto 0 & 115 & 2 \\
ano todo) & & \\
Marca & 312 & 6 \\
Vida de prateleira (durabilidade) & 250 & 5 \\
Praticidade (fácil de transportar e utilizar) & 362 & 7 \\
Ausência resíduos de agrotóxicos & 550 & 11 \\
Origem & 560 & 11 \\
Certificação & 225 & 4 \\
Meio ambiente & 250 & 5 \\
Valor nutricional & 289 & 6 \\
Valor funcional & 312 & 6 \\
Valorização de aspectos sócio-culturais & 184 & 3 \\
Outros (sem parasitas, livre de microrganismos patogênicos e & 57 & 1 \\
livre de transgênicos) & & \\
\hline Total & $\mathbf{5 2 0 0}$ & $\mathbf{1 0 0}$ \\
\hline
\end{tabular}




\section{AGRADECIMENTO}

Ao CNPq, pelo auxílio à pesquisa e bolsas PG, e ao MAPA, pelo auxílio à pesquisa.

\section{REFERÊNCIAS}

ANDRIGUETO, J.R.; KOSOSKI, A. R. Desenvolvimento e conquistas da Produção Integrada de frutas no Brasil-até 2004. Brasília: Ministério da Agricultura, Pecuária e Abastecimento, 2005. 10p. Relatório.

FRUTIFATOS. Escolha ocorre pela aparência e consistência. FrutiFatos, Brasília, n. 4, 2003.p. 11 - 13.

FRUTIFATOS. Além da beleza. FrutiFatos, Brasília, n. 6, 2004. p. $44-46$.
GUTIERREZ, A. S. D. Danos mecânicos em pós-colheita em pêssego fresco. 2005. $124 \mathrm{f}$. Tese (Doutorado em Produção Vegetal) - Escola Superior de Agricultura "Luiz de Queiroz", Universidade de São Paulo, Piracicaba, 2005.

LLOPIS, G.Y. Denominações de origem e indicações geográficas de produtos vitivinícolas. Bento Gonçalves: Embrapa Uva e Vinho, $1997.20 \mathrm{p}$.

LIU, R.H. Health benefits of fruits: implications for disease prevention and health promotion. In: CONGRESSO BRASILEIRO DE FRUTICULTURA, 19., Cabo Frio. Anais... Cabo Frio: SBF/ UENF/UFRuralRJ, 2006. v.1, p.36-44.

WATADA, J. Atributos de qualidade em frutas e hortaliças: percepção do atacadista, varejista e consumidor no contexto do Estado de SP. Fruti-Export, São Paulo, v.3, p.27-39, 1980. 